criticisms that I have heard. The first, inevitably, is financial. I have heard our College criticized because of the frequency of our Approval Visits relative to the other colleges, which have been approving their training schemes over a very much longer period. So there is pressure on Conveners to manage with one consuitant colleague. Adding a senior registrar, however desirable that is, increases the expense significantly, but I agree that they are likely to make the Approval Visit more effective. The other criticism I have heard, Dr Frost mentions himself. In my article I pointed out that feelings can run high during Approval Visits and there may be much frank and even aggressive discussion. Consultants have said to me that they would rather that senior registrars were not present on these occasions. I do not comment on this, which Dr Frost very reasonably describes as 'not in front of the juniors'.

Guy's Hospital Medical School

P. K. BRIDGES

London

\section{Damage to medical training through rapid change in health services}

\section{Dear SIRS}

Medical training entails learning about illness and treatment in the context of a society and health service. Rapid changes in the health service are making present training irrelevant. Resources that are essential components of therapy are being attacked by rigid financial policies. For example, many hospital Social Work departments have been unable to replace staff when funds are frozen. At least one nurse training school cancelled a term's intake of pupils without regard to the service implications for the future. According to Professor John Wing, Director of the Medical Research Council Social Psychiatry Unit: 'In a period of recession, it is well known that services develop unequally and there may be serious gaps in provision which particularly affect people with long-term disability.'

Although the Government has encouraged Regional Health Authorities to give priority to services for patients who are elderly, mentally handicapped, or mentally ill, these specialties are labour-intensive and costs continue to outstrip funding. Consequently, staff levels have fallen, dangerously in some districts, particularly in night nursing.

At the same time, changes in society, such as mass unemployment, involve an increased risk of illness, both physical and mental. This is producing a rising demand on medical and social services. Inevitably the less articulate chronically handicapped are put at a further disadvantage in the competition for dwindling services. Resettlement becomes impossible.

As psychiatrists in training from all parts of the British Isles we are opposed to public policies which lead to illhealth and impoverish services. We wish to draw attention to the consequences of such policies for our training. Unless the changes in progress are halted, little will remain but an emergency service, lean and competitive, but one for which our present training is inappropriate.

\section{Maudsley Hospital}

Chrus Thompson

\section{London SE5}

Also signed by: K. O'Donoghue, J. Gilbert, F. Mcmanus, N. Simpson, G. Carter, K. Roberts, M. Bluett, F. Margison, S. Balley, A. Le Couteur, D. Brodie, P. Thomas, J. Hollman, S. Philips, M. KACZMARCZUK.

\section{Planuing in child and fanily psychiatry}

\section{Dear Sirs}

The good physician makes sure that his treatment does not make the patient worse; we wonder if this is true of administrators.

During the further reorganization of the NHS, child and adolescent psychiatrists have had to take difficult planning decisions at short notice and without opportunity for consultation.

The Child and Family Psychiatric Service (CFPS) in Bedfordshire consists of three small clinics, and by the end of 1981 we were represented on both area and district planning teams. A CFPS area planning group consisting of practitioners, Community Physicians and Social Services adminstrators met regularly and had access to the Joint Consultative Committee (JCC) via the Joint Care Planning Team (JCPT). The consultant psychiatrists were also represented on district planning teams both for children's services and the mentally ill.

Because the area level of organization was to be abolished in the forthcoming NHS reorganization, administrators wished to disband the CFPS group. In future there would be two district health authorities within Bedfordshire, cutting off administratively one clinic in the north from two in the south. The practitioners in the CFPS group realized its importance as a base for overall planning of the service and decided to keep it in being even if its former link with the JCPT did not exist during reorganization.

The consultative documents issued by the new district health authorities did not mention CFPS Services, so all three clinics wrote pointing out that we were a psychiatric service and should be planned as such. This was accepted in the southern district, but was ignored by the northern district management team, which, without consultation, placed the CFPS in the Community Services unit. If these arrangements are confirmed, our service, split betwen two different planning units, may be worse off than before. We have, for instance, to plan jointly the training of junior psychiatrists studying for the Membership Examination, and this may be hindered by administrative separation.

At the moment our only united base is the CFPS group 
which has now become a forum for practitioners working within the boundaries of the old Area Health Authority. This offers a potential framework for strategic planning of a combined service for the two health authorities coterminous with the local authority, while the day to day spending of money will be decided at district level. An encouraging DHSS circular (HN (82) 9 (5)) recommends joint arrangements between health authorities and local authorities for the coordination of services of common interest. These include services concerned with child abuse, child and family guidance, child health, the mentally ill and the mentally handicapped.

Following reorganization, the acid test for all child and adolescent psychiatrists will be what voice they have in the new district units of management. Each unit will have an administrator and director of nursing services plus 'a senior member/members of the medical staff to whom the administrator and director of nursing services can relate' (DHSS circular HN (81) 34 (6)). Since these units will exercise not only budgetary control but also have the power to re-allocate the surplus within a budget, it is essential for child and adolescent psychiatrists to represent their client group and their specialty in the appropriate unit of management.

MichaEL BLACK JEAN HARRIS

Child and Family Psychiatric Service

The Clinic

Bedford

\section{Insanity and genius}

\section{DEAR SIRS}

We write to draw your attention and that of members of the Royal College of Psychiatrists to a glossy pamphlet advertising 'Depixol' issued by Lundbeck Limited and distributed, presumably, to all practising psychiatrists.

The pamphlet is entitled Art \& Psychosis-No. 2 Robert Schumann and contains a picture and brief biographical description of the artist, his career and his later deterioration towards the end of his life into psychosis with a statement that 'his brain was found to be one of the smallest and lightest on record in the medical history of men of genius'. Opposite is a description of 'Depixol' injections for schizophrenia and on the back an advertisement for 'Clopixol' injections.
We write to express our concern at the tone of this advertisement which we understand is one of a series depicting artists of genius as a means of drawing attention to the benefits of long-acting anti-psychotic agents. We feel that this series serves to confirm popular misinformation about artists through emphasizing the mythical association between insanity and genius, and in particular tends to confirm the widespread view of the artist as in some way unreliable, disordered and liable to dangerous outbursts.

We further feel that this does a disservice to those who are attempting to find a new relationship between the creative arts and therapy by defining the role of creativity in personal development.

We hope that others who share our concern at this style of advertising will write in to the Bulletin, or to ourselves, in order to express their views.

Department of Child and Family Psychiatry

118 Maidstone Road

Chatham ME4 6DL

Charlotte LitTle Selina Chandler Carolyn Noble

\section{Croydon Mental Hospital}

\section{DeAR SIRS}

In his review of the history of some mental hospitals (Bulletin, November 1982, 6, 195-7) the late Dr Walk omitted to mention the vital change that took place in 1903, when the new Lunatic Asylum for Croydon was called the Croydon Mental Hospital.

In January 1927 The Croydon Advertiser and Surrey County Reporter published an obituary of my father, Dr Edwin S. Pasmore, who was appointed the first Medical Superintendent of that hospital before it was opened, and attributed to him the origin of the term 'mental hospital'. Furthermore the hospital was the first of its kind in the country to have an operating theatre and $\mathrm{X}$-ray department to bring it into line with the general hospitals of the day. It has since been renamed the Warlingham Park Hospital.

Ham Gate Avenue

STEPHEN PASMORE 